\title{
Planificación del hábitat, valorización inmueble y gentrificación en la Quebrada de Humahuaca. Estudio de caso en la localidad de Tilcara, Argentina*
}

\author{
Habitat planning, real estate valorization and gentrification in the Quebrada de Humahuaca. A \\ case study in the location of Tilcara, Argentina
}

\section{Historial del artículo}

Recibido:

31 de agosto de 2021

Revisado

20 de octubre de 2021

Aceptado:

21 de noviembre de 2021

\section{Sergio Braticevic ${ }^{\mathrm{a}}$}

a Universidad de Buenos Aires, Buenos Aires, Argentina. Unidad Ejecutora CISOR, CONICET; San Salvador, Provincia de Jujuy, Argentina. Correo electrónico: sergiobraticevic@gmail.com. ORCID: https://orcid.org/0000-0002-9595-0388

* La finalidad del artículo es mostrar un fenómeno poco estudiado en la región norte argentina, por esa razón la agencia de investigación nacional (CONICET) promueve su desarrollo a través de la Unidad Ejecutora local, el CISOR. Asimismo, el autor cuenta con un cargo permanente como investigador desde 2016. Además, es parte del proyecto de investigación de la Universidad de Buenos Aires: "Aportes a los estudios de frontera a partir de la valorización inmobiliaria reciente. El caso de la Quebrada de Humahuaca", UBACyT-182BA (2018-2020).

\section{Palabras clave}

Gentrificación, planificación del hábitat, valorización inmueble

\section{Keywords}

Gentrification, habitat planning real estate valorization

\section{Resumen}

En este artículo se presenta un análisis respecto de la planificación del hábitat social en la Quebrada de Humahuaca (Argentina); Patrimonio de la Humanidad (UNESCO) desde el año 2003. Como caso de muestra se describe la localidad de Tilcara, epicentro del espacio objeto gracias a su desarrollo turístico reciente, la creciente valorización inmobiliaria y el potencial riesgo socioambiental en áreas de nuevos emplazamientos. En efecto, las últimas transformaciones en relación al ordenamiento territorial se han visto atravesadas y retroalimentadas por estos tres procesos; donde se destaca una particular gentrificación de ámbitos rural-urbanos, con la consecuente movilidad de la población local hacia áreas periféricas y de mayor peligro geomorfológico. A partir de esta breve caracterización, el trabajo se propone analizar la situación actual del hábitat; donde se examina el programa más reciente en la materia, las cifras del turismo y la actividad económica local, además de una serie de precios inmobiliarios en dólares entre 2004 y 2018. Finalmente, se arriba a la conclusión de la necesidad de obras de infraestructura habitacional e hidráulica; al tiempo de una mayor diversificación productiva -ya que se exhibe una clara dependencia de la industria del turismo- así como una dinámica intervención estatal ante un escenario de crisis económica.

\section{Abstract}

Among this article the author presents an analysis of the planification of social habitat in the Quebrada de Humahuaca (Argentina); World Heritage Site declared by UNESCO in 2003. The case study in the location of Tilcara shows up like the epicenter of the recent development of regional tourism, the increasing regional real estate valorization and its potential socio-environmental risk in new living sites. Likewise, the consequent transformation of the territorial ordering is crossed by these three processes: which the more relevant result is the gentrification in rural and urban spaces, and the expected effect of the local displacement to peripheric areas with geomorphological hazard by landslides. At the same time, the investigation intervenes in the phenomenon of social and land living, examining the more recent habitat planning program, the economic activities (specially the tourism) and different series of real estate values (in US dollars), between 2004 and 2018. Finally, the conclusion asserts in the urgent requirement of hydraulic and infrastructure public policies, improving the social habitat situation; also, proposes the productive diversification to counter the actual dependence of tourism industry; additionality, further statal intervention in the face of economic crisis 


\section{Introducción}

El objetivo principal del presente artículo se centra en relacionar de manera crítica tres procesos, a saber: en primer lugar, una específica forma de "gentrificación" en localidades de tamaño pequeño y semirurales, especializadas en la industria del turismo; en segundo término, el consecuente desplazamiento de su población local hacia áreas periféricas y con mayor riesgo geomorfológico; por último, la progresiva valorización inmobiliaria producto de la propia dinámica del mercado a nivel regional, además de la declaración de Patrimonio de la Humanidad por la UNESCO en 2003.

Asimismo, el fenómeno de la propiedad inmueble se encuentra atravesado por otros factores, tales como la variación del tipo de cambio, los ciclos inflacionarios y su característica distintiva de operar como "reserva de valor" para el caso argentino. En consecuencia, los desarrollos inmobiliarios locales se ven empujados tanto por el turismo, como por las posibilidades de valorización en el marco de una economía marcada por los recurrentes ciclos de crisis financiera.

En este contexto, se intenta demostrar las interrelaciones existentes en el proceso de producción de espacio, tanto local como regional; a través de conceptos clave, como gentrificación, valorización inmobiliaria y desarrollo turístico. Más adelante, se identifican diversos dispositivos que influyen en la segregación socioespacial del área, con eje en la valorización de la tierra, las transformaciones habitacionales, las distintas migraciones, la provisión de servicios públicos y los cambios recientes en los usos del suelo.

\section{Breve conceptualización}

Al compás de lo descrito hasta aquí, el incremento de los valores de la propiedad de la tierra provocó que se intensificaran los procesos de segregación periurbana, situación que se tradujo en la relocalización poblacional sobre áreas con escasa centralidad, desprovistas de servicios básicos y con elevados niveles de riesgo socioambiental. No obstante -como se analizará a continuación- se requiere abordar la noción de gentrificación con sumo cuidado, en un espacio de característica semirural y con circuitos de movilidad que provienen de épocas coloniales y prehispánicas, en algunos casos.

En este punto se realiza una distinción: los procesos de gentrificación estudiados, que usualmente pertenecen a casos urbanos y de grandes metrópolis, inherentemente han supuesto un desplazamiento masivo la de población desde espacios centrales y degradados de oficinas o baldíos (Mendoza, 2016). Esta situación sugiere una contradicción lógica, ya que muchos de estos lugares se encontraban desocupados. Para el caso de América Latina, la gentrificación en el ámbito urbano se ha dado más en la periferia que en el centro urbano; con el desarrollo de barrios cerrados y nuevas centralidades que se orientan a las clases sociales ascendentes (Lorenzen, 2021). Sin embargo, en el contexto periurbano de la Quebrada, es de presumir que se adoptaron comportamientos específicos. En síntesis, el incremento del turismo desde mediados de la década pasada se vivificó en la venta de viviendas y terrenos baldíos en el casco urbano; muchas veces a precios sumamente elevados. Esta particular característica hizo posible la capitalización de ciertos propietarios de vivienda única, que en algunas ocasiones subdividieron sus propiedades; además de disponer su comercio familiar hacia la naciente industria del turismo. De todos modos, solo fueron algunos casos, hecho que no se puede generalizar.

A escala regional, la Quebrada de Humahuaca posee circuitos de movilidad múltiple, que deben ser tenidos en cuenta si se trata la cuestión del hábitat social (Ortiz Flores, 2012). Las migraciones desde el sur boliviano, el regreso de los obreros por el cierre de las minas durante los años noventa, la trashumancia ganadera desde la zona este de los valles de la precordillera y la población no originaria proveniente desde las ciudades del sur urbano (Tucumán, Córdoba, Rosario y Buenos Aires) han marcado diferentes territorialidades sobre un espacio sumamente complejo. En este punto, es interesante abordar el concepto de transterritorialidad. De manera breve, se puede definir como "la superposición, la imbricación y la convivencia conjunta de territorios, o ese tránsito tan frecuente para algunos grupos por territorios diferentes" (Haesbaert, 2013, p.38).

De manera reciente, la región recibió inversiones públicas en infraestructura; tales como caminos, tendido eléctrico, servicios de red; situación que supuso un notable impulso en materia de turismo, principal motor del crecimiento económico del área. Dicho proceso estableció las bases para el proceso de valorización y expansión de la frontera inmobiliaria. Este último concepto puede definirse como fajas de espacio físico o tierras que pasan a ser ofertadas en el mercado inmobiliario (antes fiscales); o bien, áreas que incrementan de manera ostensible su valor de mercado; o que debido a un cambio en el uso del suelo se valorizan de manera creciente (pasando a ser parte del ámbito urbano, otrora rural). Este proceso 
de denomina acaparamiento de tierras (Costantino, 2016). Las circunstancias descriptas sucedieron de forma simultánea durante los últimos veinte años, alterando las condiciones habitacionales de la Quebrada, en general; y de Tilcara, en particular. A esto, se le sumó el escenario de la pandemia COVID-19 que trazó una fuerte baja de los precios inmobiliarios (sumada a las sucesivas devaluaciones de la moneda local y a la existencia de un tipo de cambio paralelo).

Aquí, comienza a operar la noción de renta de la tierra, concepto que remite a las diferencias de fertilidad, localización y el capital invertido en el suelo. No obstante, cabe señalar otros aspectos que influyen en los tipos de renta, tales como la competencia por los usos del suelo en el ámbito periurbano y semirural. Según Jaramillo (2003):

En el contexto de los terrenos de una ciudad observamos que ella constituye la magnitud mínima de las rentas de todos los lotes urbanos: esa será la renta de los terrenos marginales en la ciudad que no tienen ninguna otra ventaja, y sobre ella se estructuran las otras rentas. Para el conjunto de los terrenos de la ciudad opera entonces como una renta absoluta, y por ello la llamamos renta absoluta urbana. (p. 37)

En este escenario, incluso la tierra más desprovista de servicios y con peor localización soporta este tipo de renta en el espacio urbano, mientras que las tierras rurales -en general- observan un nivel menor de renta. Aquí entran en juego otros factores, tales como la traducción de las rentas en precios del suelo (debe sumarse el constructo sobre el terreno, la provisión de servicios y la localización relativa); situación que determina un nuevo precio y conforma lo que se denomina como renta absoluta urbana (Parias Durán, 2010). Este sería el caso de tierras que pasan de usos rurales a urbanos, producto de la creciente valorización de la tierra gracias al incremento del turismo (como la Quebrada de Humahuaca); en el marco de un proceso que podría catalogarse de gentrificación rural (Gascón \& Cañada, 2016).

\section{Materiales y métodos}

Para la presente investigación, se trabajó con una serie de precios de la tierra entre 2004 y 2018 , donde se realizaron entrevistas con ocho agentes inmobiliarios de la zona: Tierras Norte, Roca, ExcoNort, Aguado, La Red, Agostini, Bellomo y Noroeste; además de oferentes particulares. Por su parte, registraron todos los avisos clasificados del diario El Tribuno de Jujuy. La muestra final implicó un total de 242 registros, cifra más que considerable para el área de estudio; de los cuales 165 pertenecen a los clasificados del mencionado diario, 46 son de relevamiento propio y 31 producto de entrevistas con los corredores de las citadas inmobiliarias; así, se totalizaron unos 271.239 $\mathrm{m}^{2}$ de oferta de tierras. Todos los precios se tomaron en pesos argentinos (ARS) y se convirtieron a dólares (US\$); así, se presentan los valores de las propiedades a precios constantes y corrientes a partir de la inflación de la divisa norteamericana, de acuerdo al lapso temporal estudiado. Específicamente, para el caso de los terrenos se verificó una cantidad variada de loteos urbanos orientados principalmente al desarrollo turístico o a la construcción de segunda vivienda; mientras que, los lotes ubicados en zonas periurbanas son ofertados para el cultivo por riego o como primera vivienda, sin provisión de servicios. Se visualizó una gran dispersión de precios entre las áreas urbanas y periurbanas.

Por su parte, el análisis se centra en la localidad de Tilcara, ya que se trata del lugar más concurrido. Adicionalmente, y para completar la muestra, se analizan precios inmobiliarios de cuatro localidades: Purmamarca, Maimará, Huacalera y Humahuaca; todas ubicadas en la ecorregión de sierras, sinónimo de la quebrada y la zona más turística de la provincia (figura 1). No obstante, se cuenta con valores de 2019 y 2020 , pero la muestra es menor y más difícil de sistematizar, ya que las restricciones existentes no permitieron recolectar mayor cantidad de datos; al menos durante el último año, que coincidió con el inicio de la pandemia. Puede haber sucedido que ante dicho contexto, se prefiriera salir de las grandes ciudades hacia ámbitos rurales o viviendas de mayor tamaño, pero se trata solo de un disparador para futuras pesquisas en la materia (para más información, consultar: De Toro, Nocca \& Buglione; 2021).

Por último, el programa examinado - pero no implementadoes el Plan Estratégico Urbano Ambiental de la Localidad de Tilcara (PEUA) del año 2018. Además, se cuenta con cifras pertenecientes a la industria del turismo, así como una ponderación de las actividades productivas y de servicios para el mismo año, dato enormemente valioso para una región semirural que no cuenta con este tipo de estadísticas. En este sentido, no se registran números fehacientes sobre migraciones y movilidades en el área; aunque sí se comprueba en los catastros de tierras y en la atención hospitalaria la existencia de personas provenientes de otras zonas. No obstante, ha sido sumamente engorroso y difícil contar con este tipo de fuente estadística. 


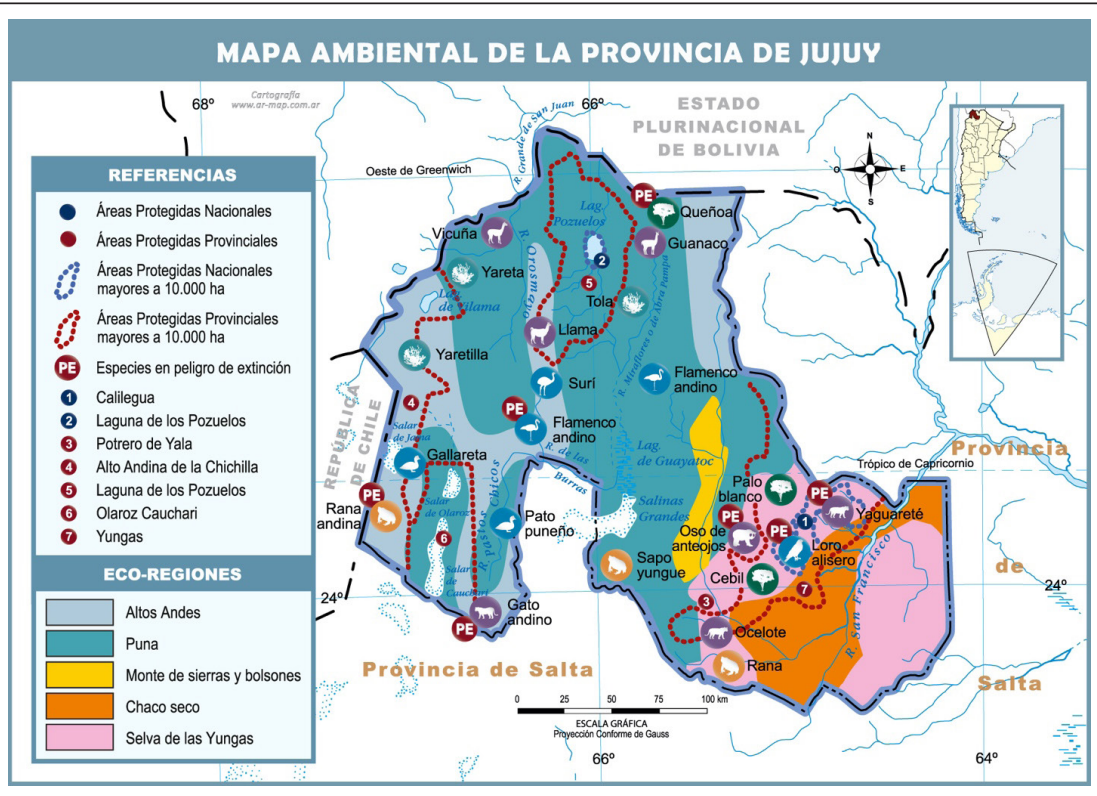

Figura 1. Ecorregiones de la Provincia de Jujuy y posición relativa en la República Argentina. Fuente: Mapoteca Educ.ar (2021).

\section{Resultados}

Mercado inmobiliario, hábitat y gentrificación. Comportamiento reciente del mercado de tierras.

El espacio objeto, la Quebrada de Humahuaca - Patrimonio de la Humanidad por la UNESCO a partir de 2003-, observó múltiples alteraciones en la utilización del suelo durante los últimos años. En consecuencia, pasa de ser un lugar de cultivo por riego en pequeñas parcelas, a conformarse como lugar orientado al turismo. Producto de dicha situación, se genera un mercado de tierras orientado a la inversión hotelera a partir de desarrollos turísticos de media y alta gama. Asimismo, las zonas de cultivo se desplazan a zonas rurales más alejadas y al norte, como es el caso de Villa El Perchel, Huacalera, Uquía y las afueras de Humahuaca, la ciudad más populosa de la Quebrada. Por aquella época, hace alrededor de quince años, en la localidad de Tilcara existían muchos terrenos baldíos cercanos al centro urbano. No solo se urbanizaron lotes otrora rurales, sino que también se construyeron emprendimientos orientados al turismo en tierras disponibles con una centralidad creciente. Este tipo de valorización inmobiliaria se encuentra estrechamente relacionada con la gentrificación urbana, que implicó desplazamientos de la población local hacia las afueras, aunque no en todos los casos. Por su parte, la denominada gentrificación periurbana se desarrolló en terrenos generalmente arrendados que pasaron a manos de inversores privados perteneciente a la industria del turismo. A continuación, se muestra uno de los loteos recientes de la localidad de Tilcara, próximo al centro distrital, en uno de los faldeos perimetrales del ejido urbano (figura 2).

Con particularidades y continuidades, las distintas localidades de la Quebrada de Humahuaca vivificaron acelerados procesos de cambio en su morfología urbana a partir de la intensificación del turismo y el aumento de los precios de las propiedades. Para la presente investigación, se exhiben cinco localidades: Purmamarca, Tilcara, Maimará, Huacalera y Humahuaca. La primera de ellas se constituyó como la más cara y promocionada del área objeto (Braticevic, 2018). Así, Purmamarca ha sido la localidad donde mayor interacción observaron los procesos de patrimonialización y turistificación. Dicha situación implicó que la población local se trasladara -en partehacia urbanizaciones polares o discontinuas del ejido urbano principal, las comunidades indígenas de Chalala y Coquena (Tommei \& Benedetti, 2014). Allí, los valores del metro cuadrado de terreno con servicios se incrementaron casi un $800 \%$, en dólares, entre 2004 y 2018 .

Hasta hace poco tiempo, se hablaba de una distorsión de precios debido a las expectativas generadas gracias a las futuras adquisiciones de agentes extranjeros y nacionales (desde los grandes aglomerados urbanos). Sin embargo, de acuerdo a lo verificado en diversas entrevistas, estas compras no se dan tan a menudo; más bien, se realizan 
Tabla 1

Precios por metro cuadrado de terreno limpio y con servicios. US\$ a valores corrientes. Quebrada de Humahuaca. Años 2004, 2011,2016 y 2018.

\begin{tabular}{lccccc}
\hline Año & 2004 & 2011 & 2016 & 2018 & Variación Porcentual (\%) \\
\hline Localidad & \multicolumn{3}{c}{ US $\$ \mathrm{~m}^{2}$} \\
\hline Purmamarca & 20 & 74 & 142 & 157 & 785 \\
\hline Tilcara & 22 & 48 & 96 & 108 & 491 \\
\hline Humahuaca & 8 & 38 & 50 & 54 \\
\hline Maimará & 22 & 35 & 32 & 48 & 245 \\
\hline Huacalera & 16 & 25 & 84 & 88 & 300 \\
\hline Quebrada & 20 & 45 & 32 & 440 \\
\hline
\end{tabular}

Fuente: Elaboración propia con base en relevamientos con inmobiliarias de la zona, trabajo en terreno y avisos clasificados del diario El Tribuno.

Tabla 2

Precios por metro cuadrado de terreno limpio y con servicios. US\$ a valores constante. Quebrada de Humahuaca. Años 2004, 2011,2016 y 2018.

\begin{tabular}{|c|c|c|c|c|c|}
\hline Año & 2004 & 2011 & 2016 & 2018 & \multirow{2}{*}{ Variación Porcentual (\%) } \\
\hline Localidad & \multicolumn{4}{|c|}{$\mathrm{US} \$ / \mathrm{m}^{2}$} & \\
\hline Purmamarca & 20 & 62 & 88 & 119 & 595 \\
\hline Tilcara & 22 & 40 & 75 & 82 & 373 \\
\hline Humahuaca & 8 & 32 & 39 & 42 & 525 \\
\hline Maimará & 22 & 30 & 33 & 41 & 186 \\
\hline Huacalera & 16 & 14 & 25 & 36 & 225 \\
\hline Quebrada & 20 & 38 & 66 & 67 & 335 \\
\hline
\end{tabular}

Fuente: elaboración propia con base en relevamientos con inmobiliarias de la zona, trabajo en terreno y avisos clasificados del diario El Tribuno. Deflactado a partir de index USCPI31011913, Bureau of Labor Statistics (FXTOP, 2020)..

por parte de actores privados de las ciudades más cercanas del norte argentino (San Salvador, Salta y Tucumán). Adicionalmente, el boom turístico-hotelero e inmobiliario se encontró traccionado por la devaluación del peso argentino durante 2002, hecho que impactó positivamente sobre los precios relativos en dólares (con una notable tendencia a la baja, haciendo posibles las transacciones para quienes poseían ahorro en moneda extranjera). Así, el ascenso de los precios se mantuvo relativamente constante entre 2004 y 2016, cuando comenzó a ralentizarse; cuando se comienzan a registrar menores subas. A remolque de las sucesivas devaluaciones a partir del año 2018 y el comienzo de la pandemia durante el 2020; los valores se estancaron $\mathrm{y}$-en algunos casos- sufrieron caídas, siempre denominándose en dólares.
En la tabla 1 pueden identificarse los precios a lo largo del período estudiado. Como se observa, los incrementos porcentuales varían entre un $785 \%$ y un $245 \%$ según el caso. En este primer ejemplo, se muestran los valores en moneda extranjera a precios corrientes (sin contabilizar la inflación del dólar, ni la emisión monetaria por parte de la Federal Reserve Board - FED).

En contraposición, si se resta la inflación según el índice de precios de los Estados Unidos, las variaciones de precios son menores, pero también contundentes. En la Tabla 2 se observan los valores constantes -en dólares- desde 2004 a 2018. En todos los casos, se registraron precios en ascenso según la localidad. 


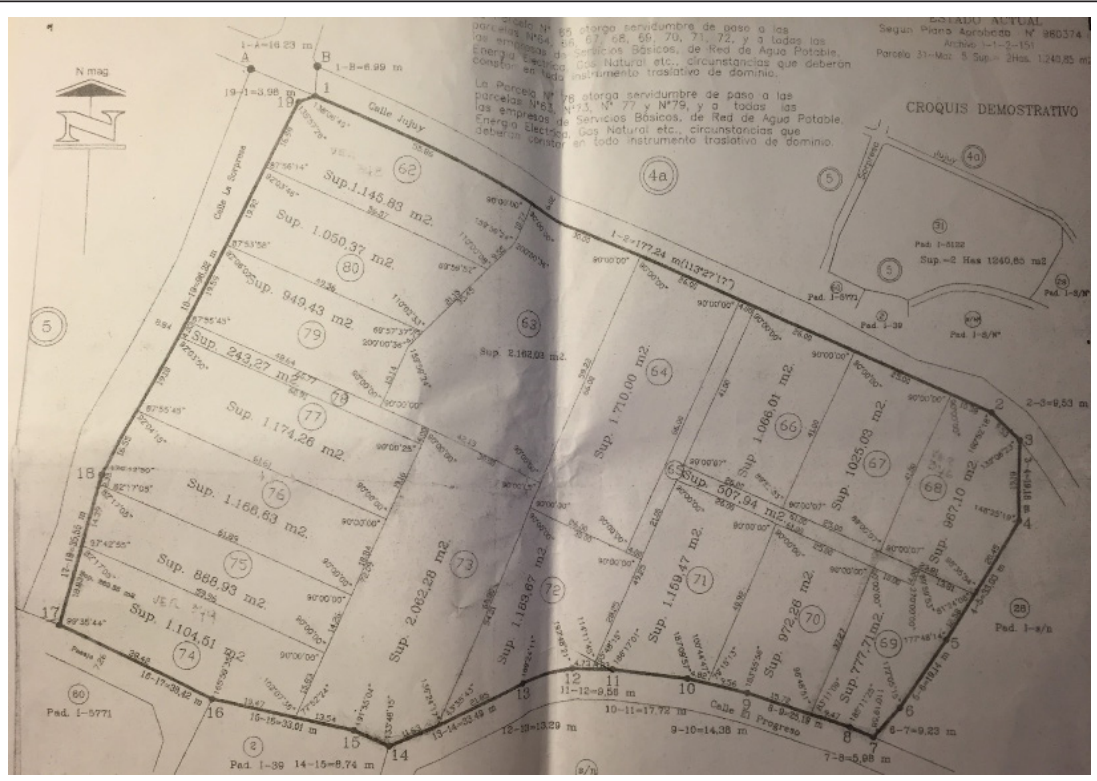

Figura 2. Subdivisión del lote padrón I-5122. Localidad de Tilcara, año 2016. Fuente: fotografía propia tomada en la Dirección Provincial de Inmuebles de Jujuy, 20 de octubre de 2016.

De forma particular, las localidades de Tilcara y Humahuaca dependen -mayormente- del mercado interno, mientras que Purmamarca se encuentra más vinculada al internacional. Por esta razón, en las dos primeras localidades se ha registrado un estacionamiento de los precios en dólares desde hace unos años, producto de la saturación de hoteles y la merma del turismo interno. Por su parte, Huacalera y Maimará poseen una lógica diferente, ya que se ven áreas periurbanas de pequeñas chacras con trabajo intensivo y gran capacidad de ahorro (con trabajo familiar y elevados niveles de autoexplotación). En la tabla 3 se muestra la cantidad de tierra ofertada durante el período estudiado. Las localidades de Huacalera y Humahuaca concentran el $52 \%$ de la oferta, le sigue Purmamarca con el $11 \%$, Tilcara con el $8 \%$ y Maimará con el 6\%. Otras localidades tales como Villa El Perchel, Juella, Chucalezna y Uquía poseen una disponibilidad rural y dispersa, aunque con el $24 \%$ del total en el lapso examinado.

Los datos que pudieron relevarse hasta el momento muestran que los valores alcanzados durante 2016 (alrededor de 84 US\$) treparon hasta los 88 US\$ en 2018, mientras que para el año 2020 no llegan siquiera a los 90 US\$. Esto se debió a un doble proceso; por un lado, los precios habrían tocado un techo a raíz de la sobreinversión; por el otro, los efectos de la pandemia reflejan muy bajas perspectivas para el sector turístico en el corto plazo. Todo ello, en un escenario con suspensión de vuelos, cierre de comercios y merma del poder adquisitivo, entre otros factores. En
Tabla 3

Oferta total en metros cuadrados. Quebrada de Humahuaca. Años 2004-2018.

\begin{tabular}{lcc}
\hline Localidad & $\mathrm{m} 2$ & Porcentaje \\
\hline Huacalera & 93.224 & $34 \%$ \\
\hline Humahuaca & 47.486 & $18 \%$ \\
\hline Purmamarca & 28.524 & $11 \%$ \\
\hline Tilcara & 21.105 & $8 \%$ \\
\hline Maimará & 15.575 & $6 \%$ \\
\hline Otras & 65.325 & $24 \%$ \\
\hline Total & 271.239 & $100 \%$ \\
\hline
\end{tabular}

Fuente: Elaboración propia con base en relevamientos con inmobiliarias de la zona, trabajo en terreno y avisos clasificados del diario El Tribuno.

la figura 3, más arriba, pueden verse los precios para los lotes con servicios en las localidades seleccionadas, entre 2004 y 2018.

\section{Incremento poblacional, migraciones y usos del suelo}

Al compás del aumento de los precios inmobiliarios y las actividades turísticas, el crecimiento de los ejidos urbanos se verificó a lo largo y ancho de la Quebrada 


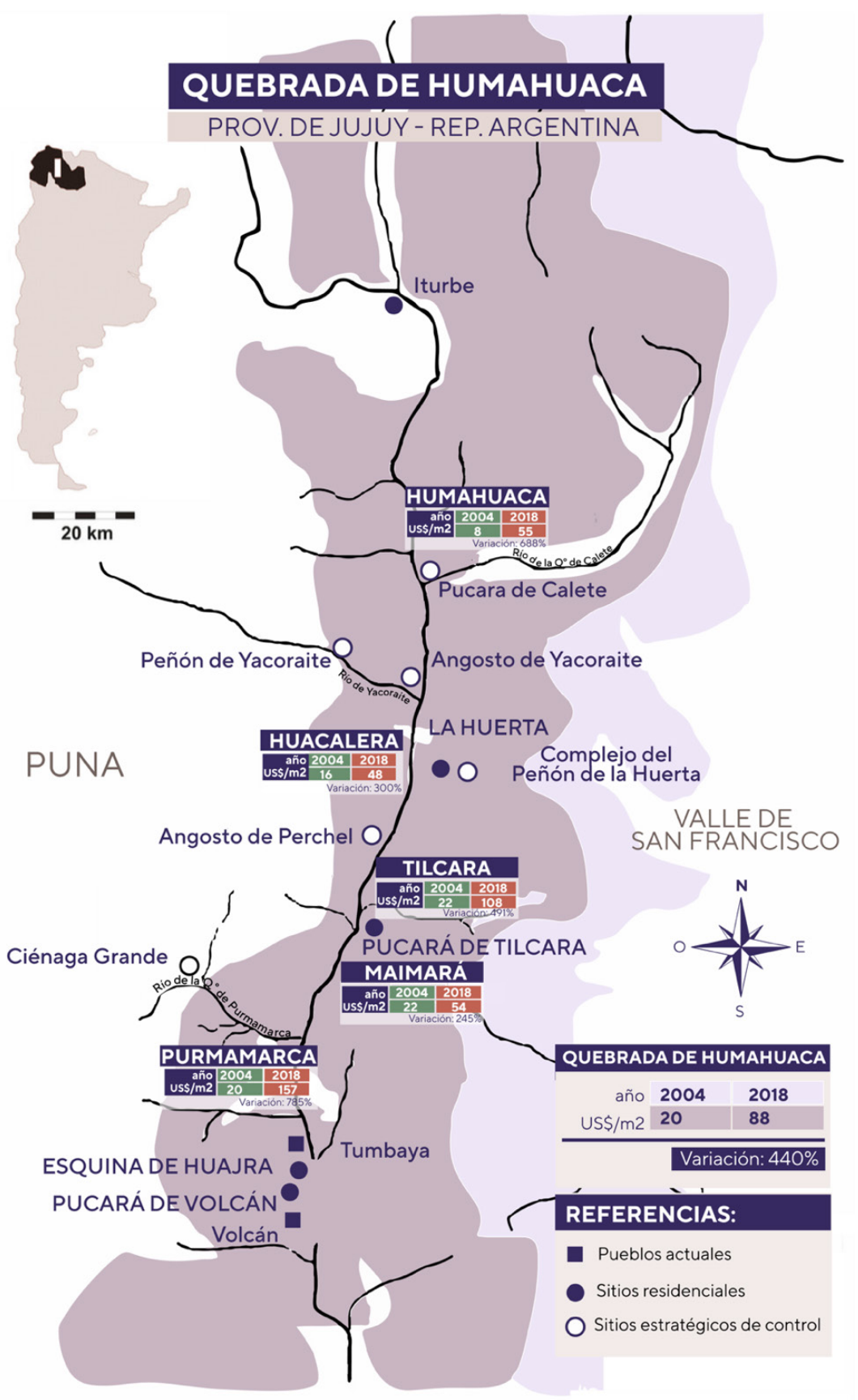

Figura 3. Precios de la tierra por metro cuadrado en dólares. Quebrada de Humahuaca. Años 2004-2018. Fuente: Minaglia \& Bages con base en Ochoa (2017). 
de Humahuaca. Así, la población se incrementó desde el año 2000 a la actualidad en casi un $40 \%$, pasando de alrededor de 30.000 habitantes a unos 42.000 para el año 2020; según estimaciones provinciales. A su vez, la Provincia de Jujuy cuenta con una gran proporción de población indígena; ya que más del $30 \%$ se autorreconoce como originaria. La principal actividad es el turismo y todos sus servicios relacionados; además de las tierras orientadas a cultivos. Para el caso de Tilcara, se estima que la población residente en el ejido urbano asciende a más de 12.000 habitantes, mientras que el departamento se encuentra por encima de los 16.000 (se incluyen las zonas rurales). Dichas cifras se calculan en base a Censo Nacional de 2010 (DiPEC, 2021).

Por su parte, la Dirección Provincial de Estadísticas de Jujuy no cuenta con las cifras de movilidad interna, solo muestra que alrededor de un $5 \%$ de la población del departamento es extranjera. De cualquier forma, los catastros muestran que una porción considerable de las propiedades posee dueños de otras provincias $\mathrm{y}$, en algunos casos, extranjeros. Otro fenómeno por destacar es la multiresidencialidad, relacionada con los movimientos migratorios constantes, ya sea desde zonas de la Puna, como desde los Valles de las Yungas (figura 1). La cría de la hacienda es trashumante y se desplaza hacia la Quebrada desde la primavera y hasta el final del verano; la "veranada" se realiza en esta región gracias a las condiciones favorables del estío (mayor disponibilidad de agua y mejores pasturas). Generalmente, esta población se ubica en las afueras de Tilcara, donde permanecen solo durante el verano. Por otra parte, en las parcelas periurbanas de otras localidades, tales como Maimará, Huacalera, Villa El Perchel, Uquía y Humahuaca, se ubican finqueros de origen boliviano (Departamento de Potosí) que arriendan tierras para cultivo con riego. Diversos trabajos en terreno muestran las características descriptas, ya que no existen estadísticas oficiales al respecto. Por último, a los despidos en las minas durante los noventa, se le suman los recientes cierres de la Compañía Minera Aguilar y Pirquitas. Todo lo mencionado se sintetiza en más población en la Quebrada, con la particularidad que posee Tilcara: es el lugar con mayor riesgo geomorfológico sobre el emplazamiento urbano, si se la compara con el resto de la región.

En este escenario, se dificultó el acceso a la vivienda, ya que entraron en disputa mayor número de demandantes de tierra; especialmente, todas las actividades relacionadas con el turismo, como la hotelería y los comercios asociados. En consecuencia, distintos grupos entraron en pugna por el espacio en dicha localidad. Así, los actores menos favorecidos se ubicaron sobre los sectores más alejados, con menor provisión de servicios públicos y mayor riesgo ambiental (los faldeos con mayor pendiente). Aquí, es necesario realizar una breve aclaración: el tipo de gentrificación se dio en algunos casos con la población residencial ya existente, pero la especificidad de Tilcara es que a este fenómeno se le sumaron diferentes migraciones. En efecto, se desarrollaron cambios en la utilización del suelo, conforme con todos los procesos analizados. En la figura 4 pueden verse los usos del suelo, la infraestructura urbana y los precios en dólares para el año 2016.

\section{Desarrollo turístico, riesgo socioambiental y planes de mitigación}

En la tabla 4 se muestra una ponderación de las actividades económicas del Municipio de Tilcara, a precios corrientes, para enero de 2018. Las estimaciones surgen de la Jefatura de Gabinete Municipal, mientras que las cifras obtenidas se corrigieron "en terreno" de acuerdo a cada rubro y situación (entre abril y mayo del mismo año). En este punto, vale la pena aclarar que la economía argentina registra marcados ciclos de crecimiento y crisis, marcados por sucesivas devaluaciones de la moneda local y altos niveles de inflación. Por esta razón, los valores de referencia deben ser analizados en dicho contexto.

De manera sucinta, se puede asegurar que el sector del turismo compone el $30 \%$ de la actividad total, sin contabilizar rubros conexos tales como el comercio, la venta callejera y los servicios de transporte (taxis y traslados); que, si bien no están enteramente dedicados a la industria del turismo, se calcula que un 70\% sí depende de dicha actividad. Incluso, si se realiza esta corrección, alrededor del $60 \%$ de los ingresos totales y casi el $50 \%$ del empleo dependen del sector turístico. Allí radica la enorme importancia, también la dependencia, que posee el espacio objeto respecto del turismo. En paralelo, el escaso desarrollo de las cadenas de valor a nivel local, se traduce en actividades primarias con exiguo valor agregado, cuentapropismo, empleo público y demás actividades comerciales. Cabe señalar, que la agricultura posee unas 175 hectáreas y 140 productores, con un tamaño promedio de 1,25 ha por unidad productiva. Mientras tanto, la ganadería cuenta con 50 productores, con rodeos de no más de 20 animales en pie.

En relación al flujo turístico, la localidad de Tilcara se constituye como la más visitada en la Quebrada, junto con Purmamarca. Según datos de la Municipalidad, existen más de 120 establecimientos de alojamiento y unas 2.500 plazas disponibles; sector que representa más 
Tabla 4

Sectores de la economía. Municipio de Tilcara. Precios corrientes. Enero 2018.

\begin{tabular}{|c|c|c|c|c|}
\hline Sector & Actividad & Empleos & Masa Salarial & Ingresos Totales \\
\hline \multirow{2}{*}{ Turismo } & Hotelería & 600 & 118.260 .000 & 394.200 .000 \\
\hline & Alojamientos Familiares & 55 & 1.200 .000 & 12.000 .000 \\
\hline Estatal & Dependencias Públicas & 582 & 119.471 .423 & 119.471 .423 \\
\hline \multirow{2}{*}{ Servicios } & Transporte & 300 & 32.076 .000 & 106.920 .000 \\
\hline & Autoempleo & 270 & 22.842 .072 & 34.609 .200 \\
\hline \multirow{2}{*}{ Primario } & Agricultura & 154 & 2.352 .000 & 23.520 .000 \\
\hline & Ganadería & 55 & 975.000 & 9.750 .000 \\
\hline \multirow{4}{*}{ Comercial } & Comercio & 600 & 148.262 .400 & 449.280 .000 \\
\hline & Cárnico & 200 & 35.062 .500 & 106.250 .000 \\
\hline & Vegetales & 120 & 10.625 .000 & 53.125 .000 \\
\hline & Venta Callejera & 110 & 15.937 .500 & 159.375 .000 \\
\hline \multicolumn{2}{|c|}{ Totales } & 3.046 & 507.063 .895 & 1.468 .500 .623 \\
\hline
\end{tabular}

Fuente: Elaboración propia en base a Jefatura de Gabinete, Municipalidad de Tilcara (2018).

del 30\% de la economía local (Municipalidad de Tilcara, 2018). La última escala del circuito turístico suele ser Tilcara, debido a que se trata de una distancia óptima desde Salta, ciudad que - de alguna manera- centraliza en turismo regional en dirección norte. A propósito, en la ciudad de Salta se localizan gran parte de las agencias de turismo y el aeropuerto con mayor flujo de la región. Según datos oficiales, el Aeropuerto Internacional de Salta registró un total de 1.111.000 pasajeros durante 2018 . Así, se ubicó en el sexto lugar a nivel nacional, por lo que supera a Tucumán (933.000) y a Jujuy (395.000), los otros aeropuertos de la región (EANA, 2018). En efecto, gran parte del turismo dentro de la Provincia de Jujuy es coordinado desde Salta, próxima a unos $150 \mathrm{~km}$ de la Quebrada de Humahuaca. Por su parte, este circuito se estructura con Purmamarca y Tilcara como vértices, en paquetes turísticos de no más de una semana y con bajos niveles de permanencia. Según la Jefatura de Gabinete de Tilcara, la estadía promedio en esta localidad es de apenas dos días (2018).

Por su parte, la morfología urbana local se corresponde -de manera directa o indirecta - con la analizada industria del turismo. Predomina, entonces, un "paisaje turistificado" que pierde homogeneidad al distanciarse del centro. Un poco más lejos, los barrios localizados sobre los faldeos de las montañas, con menor provisión de servicios y mayor riesgo ambiental, registran niveles de segregación socioespacial respecto del centro urbano. Dicha situación, se traduce en una producción diferencial de hábitat que se observa en apenas cientos de metros. El paisaje descrito predomina en Tilcara y, principalmente, en la vecina localidad de Purmamarca. Se suele hablar de esta última como la "ciudad-huerta" que se convirtió en el pueblo boutique de la Quebrada de Humahuaca (Tommei \& Benedetti, 2014).

A contramano, no sucede lo mismo en el resto de las unidades urbanas, tales como Maimará, Huacalera y Humahuaca, que conservan una morfología más similar a la conocida de manera previa a la declaratoria de patrimonio. No hay que olvidar a la emergente localidad de Sumay Pacha, mancha urbana que creció rápidamente desde 2002. Este poblado se localiza entre Maimará y Tilcara, equidistante a 4 kilómetros de cada una de ellas. Se trata de una zona sumamente riesgosa - a nivel geomorfológico- ya que se encuentra sobre un abanico aluvial. De manera inicial, se efectuó una toma de tierras, que años después derivó en un plan de vivienda social; más precisamente de 122 unidades. Más tarde, se fue poblando a medida que iba creciendo el turismo en la Quebrada, hasta alcanzar casi unas 500 viviendas y unos 2.500 habitantes, veinte años después. Así, se fue poblando como la "ciudad 


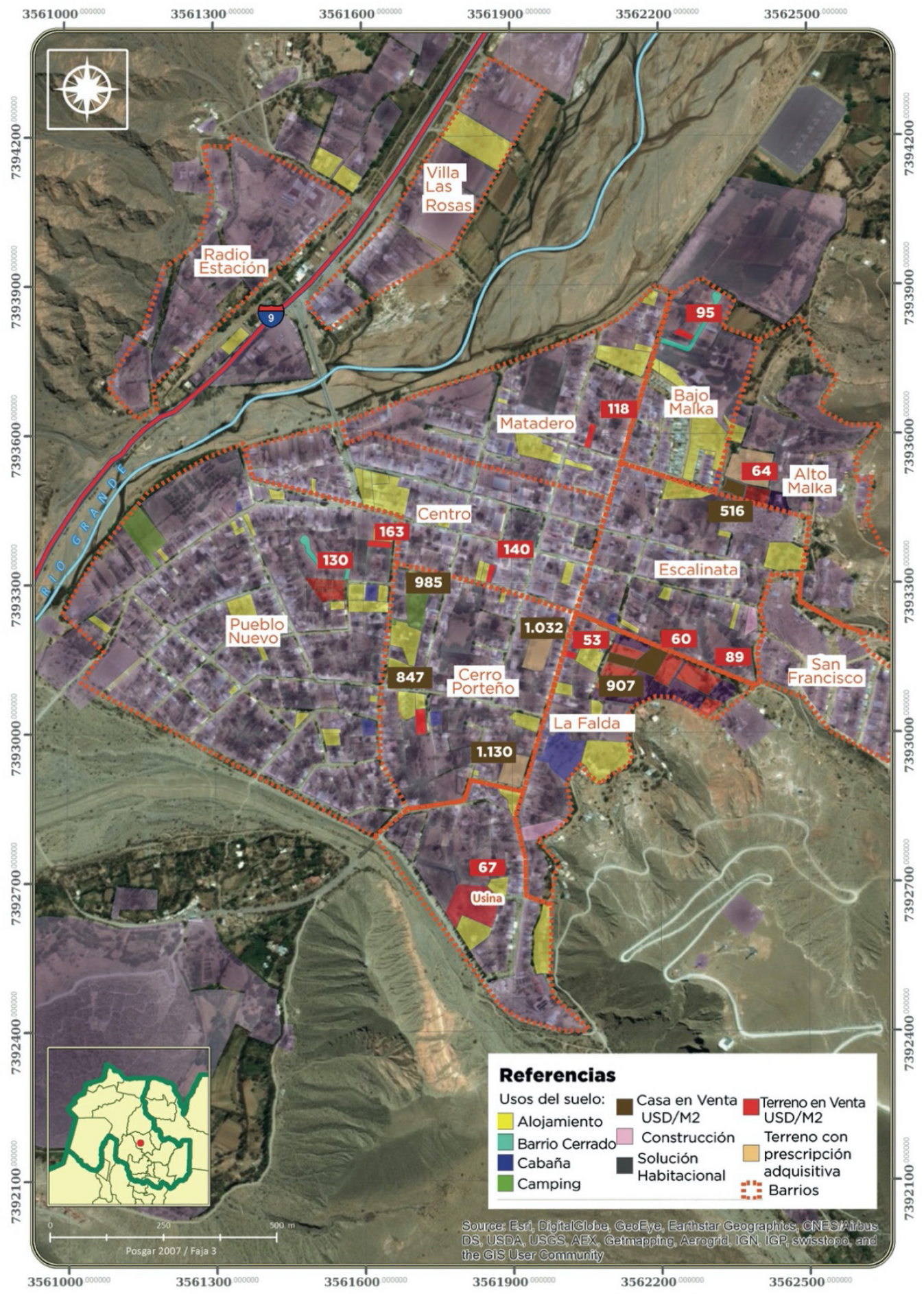

Figura 4. Usos del suelo, infraestructura urbana y precios inmobiliarios (m2/US\$). Tilcara (2016). Fuente: elaboración con base en relevamiento propio (2016) y Dirección Provincial de Inmuebles (2016), en conjunto con Minaglia \& Bages (2020). Sistema de coordenadas: POSGAR 2007, Faja 3. Realizado con software libre: QGIS Las Palmas 2.18.9. 
satélite" de Tilcara, con la fuerza de trabajo empleada por el turismo regional, a la vez que se fueron levantando distintas construcciones que desbordaron largamente la planificación original (Potocko, 2013). Al tratarse de terrenos otrora fiscales (más tarde parte de un programa de hábitat), no se pudieron tomar precios, pese a que sí existe un mercado informal de compraventa de terrenos.

Ahora bien, para el caso analizado, Tilcara posee un "Programa Integral de Hábitat" con tres módulos (regularización dominial, desarrollo social y mejoramiento urbano), que se traduce en un Plan Estratégico Urbano Ambiental (PEUA), con su respectivo Estudio de Impacto Ambiental y Social (EIAS). Todo ello emana del Ministerio de Obras Públicas Nacional y el Ministerio de Infraestructura, Servicios Públicos, Tierra y Vivienda de la Provincia de Jujuy; estudios efectuados durante el año 2018. Finalmente, dicho programa no fue ejecutado, pese a contar con los fondos de la Comisión Andina de Fomento (CAF). Como se indica en el Boletín Oficial del día 7 de junio de 2021, se suspende la realización de la principal obra de dicho programa, el puente sobre el Río Grande en el acceso norte. Queda así sellada la clausura del PEUA, al menos en el mediano y corto plazo (Boletín Oficial, 2021).

Si bien contaba con tres módulos, el PEUA tenía como eje central al componente urbano, que se componía de las obras de infraestructura hídrica y urbanísticas. Las más importantes eran las primeras: sistematización de cuencas, pedemonte y banda de los ríos Grande y Huasamayo, manejo de terrazas en la cuenca media, nuevas defensas sobre el río Grande y reparación de la existente en el río Huasamayo. De haberse realizado, el potencial riesgo socioambiental se hubiera reducido considerablemente.

En la figura 5 puede observarse el plan de sistematización de las microcuencas que rodean la localidad, a través de la mitigación hídrica de las quebradas que transportan flujos de derrubios, por remoción en masa, en épocas estivales (que es cuando más precipitaciones se producen). Vale la pena destacar que Tilcara se encuentra rodeada de material sedimentario en abanicos aluviales y que parte del ejido urbano se encuentra en zona de depósito. Esto implica un enorme riesgo durante cada verano para la ciudad, ya que las lluvias suelen ser torrenciales y nocturnas.

Por su parte, el plan de obras urbanístico se componía de un nuevo puente en el acceso norte de la ciudad, una red de pavimento de hormigón y articulado, cordón cuneta, alumbrado y demás equipamiento urbano. Asimismo, se proponía construir una nueva terminal de ómnibus, un mercado regional y el parque deportivo, que se sumaría a la refuncionalización de los edificios existentes. En la figura 6 pueden identificarse algunas de estas infraestructuras.

Cabe señalar que dicho programa no contenía soluciones habitacionales ni obras de servicios públicos domiciliarios, una cuestión que sigue pendiente, más si se tiene en cuenta a los nuevos poblamientos en los faldeos de los cerros tilcareños. Si bien se realizaron diversas obras durante los últimos años -interrumpidos a causa de la pandemia- las diferentes redes permanecen incompletas. En consecuencia, el gas llega a casi un $60 \%$ de los hogares, mientras que el agua potable alcanza un $75 \%$ y los desagües cloacales a un $50 \%$; por su parte, el asfaltado a apenas un $30 \%$ y la conectividad de Internet sigue siendo bastante insuficiente (de acuerdo a relevamientos en terreno y con autoridades de las empresas públicas durante 2018).

Se suma a la situación descrita, la fuerte demanda de alquileres durante la época veraniega, además de la suba general de los precios para la temporada de turismo. Adicionalmente, a partir de la declaración de patrimonio, se instalaron familias provenientes de otras zonas de la Quebrada y de la Puna, gracias a un triple proceso: la falta de trabajo en sus lugares de origen, la posibilidad de contar con más servicios del estado y la chance de encontrar algún empleo en la industria del turismo. Al mismo tiempo, se sostuvieron los diferentes circuitos de movilidad analizados más arriba.

\section{Estado del arte, relevancia del tema y propuestas}

Si bien existe una variada indagación sobre temáticas relacionadas con la producción de espacio, el hábitat social, la patrimonialización y el crecimiento de la actividad turística a lo largo y ancho de la Quebrada de Humahuaca, son exiguos los estudios más recientes que aborden específicamente cuestiones tales como la valorización inmobiliaria, la gentrificación y el ordenamiento urbano. De todos modos, los textos citados para la presente investigación (además de los referidos en este acápite) proponen ricos análisis interdisciplinarios desde diferentes perspectivas: la geografía histórica, el enfoque regional político-cultural, el análisis socio-antropológico, solo por mencionar algunos ejemplos que examinan diversas realidades del espacio objeto (Benedetti, 2010; Tommei, 2010; Tommei \& Benedetti, 2014; Vecslir\& Tommei, 2013).

Así, el principal propósito del artículo es analizar una serie de procesos escasamente investigados en el norte argentino. Se identifica la relevancia de las problemáticas plateadas y el trabajo conjunto con las agencias estatales, 


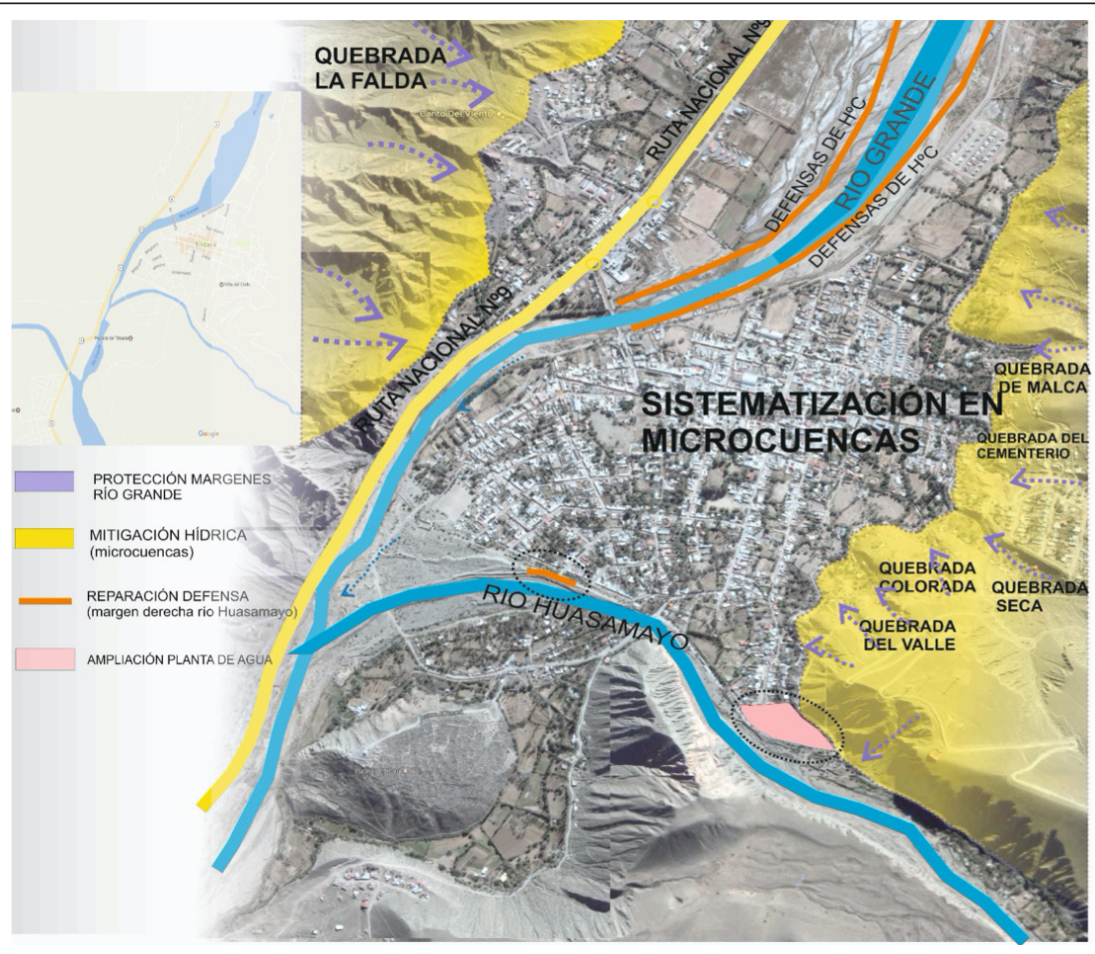

Figura 5. Riesgo socioambiental y plan de obras de mitigación hídrica. Tilcara. Año 2018. Fuente: Programa Integral de Hábitat. Ministerio del Interior, Obras Públicas y Vivienda de la Nación (2018).

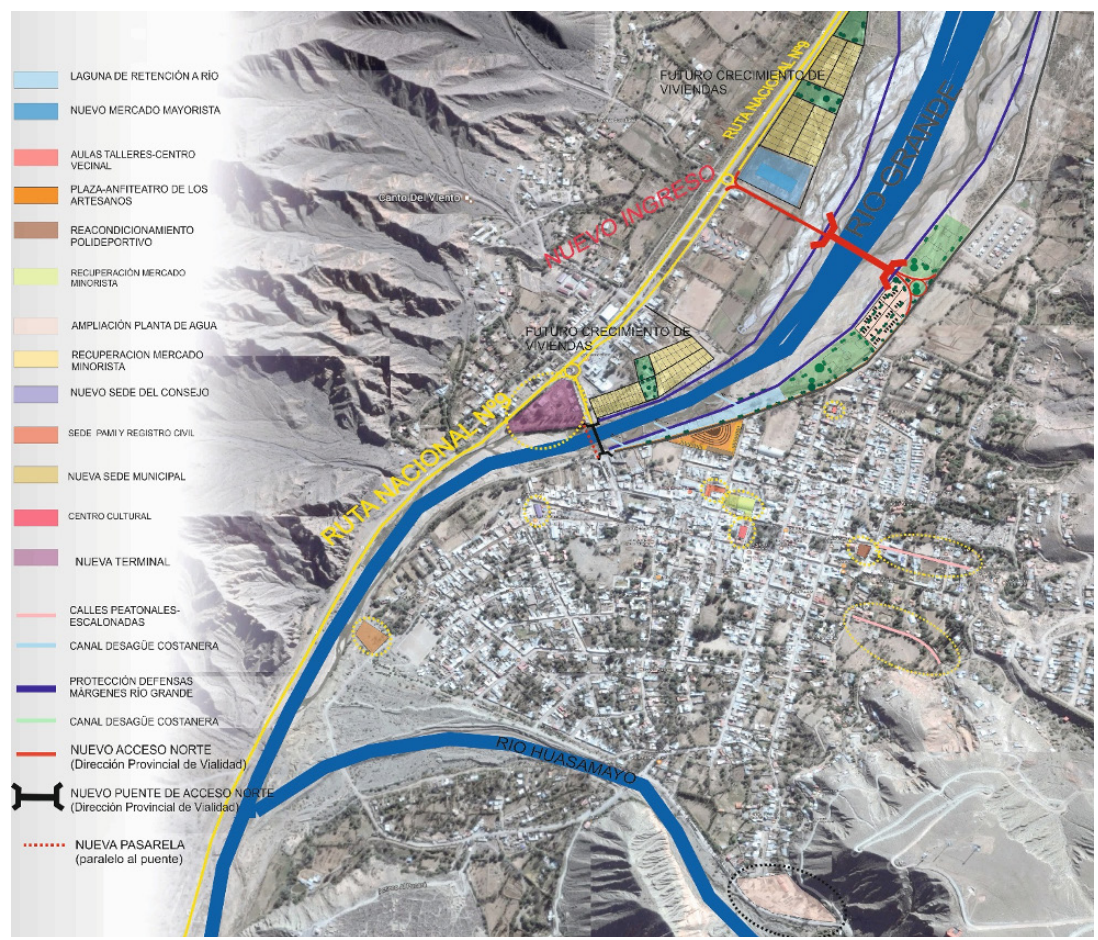

Figura 6. Reordenamiento territorial edilicio, obras hídricas y nuevo puente-acceso norte. Tilcara. Año 2018. Fuente: Programa Integral Hábitat. Ministerio del Interior, Obras Públicas y Vivienda de la Nación (2018). 
con el fin de transferir conocimiento para el ordenamiento territorial de la Quebrada de Humahuaca. Dicho lugar ha venido sufriendo grandes alteraciones durante los últimos veinte años, mientras que los distintos niveles del Estado no han logrado equilibrar los desajustes espaciales producto de los fenómenos descriptos más arriba. Por esa razón, la presente pesquisa cuenta con el aval de diferentes instituciones académicas (CONICET, UBA y UNJu) y financiamiento para su realización.

Por último, se plantea continuar con la interacción existente entre los organismos públicos y las instituciones académicas a fin de resolver las diferentes problemáticas de hábitat social regional. Por su parte, es deseable obtener información precisa sobre la población estable y temporaria a nivel local, con el objetivo de identificar la efectiva necesidad de vivienda en el marco de un tejido urbano pequeño y limitado por las zonas de riesgo socioambiental; además de reconocer el contexto de pandemia y la restricción de recursos financieros existentes por parte del estado. Todo ello, con la intención primordial de llevar a cabo el ordenamiento territorial de manera integral para el espacio quebradeño.

\section{Conclusiones}

Como se mencionó anteriormente, esta investigación versa sobre distintos tópicos poco estudiados en el norte argentino. En este sentido, se pudo identificar e interrelacionar diversos procesos concomitantes en la Quebrada de Humahuaca, específicamente analizados para la localidad de Tilcara. Así, se logró demostrar la relación entre la suba de los precios inmobiliarios con la particular gentrificación en zonas urbanas y de "borde". El aumento de los valores para tierras baldías y con servicios entre 2004 y 2018 arrojó una diferencia promedio del $335 \%$ en US\$ a precios constantes; mientras que para los años posteriores (2019 y 2020) casi no se observaron variaciones, permaneciendo prácticamente igual al tipo de cambio oficial (alrededor de los 88 US\$ el metro cuadrado de terreno limpio). No obstante, si se calcula con el dólar "paralelo", los valores se reducen en un $35 \%$. De todos modos - a fines de poseer una serie de precios extendida en el tiempo- se utilizaron cifras en US\$, aunque la mayor parte de las transacciones a nivel local se realicen en moneda doméstica (ARS). Por su parte, la cantidad de compraventas realizadas durante el último bienio fue mucho menor, debido a las sucesivas devaluaciones del peso argentino y la crisis provocada por la pandemia. Este fenómeno no fue exclusivo de la Quebrada o del norte argentino, se dio a lo largo del país y de la región. Si bien no emanan estadísticas oficiales desde la Dirección Provincial de Inmuebles de Jujuy o del Colegio de Escribanos, distintos actores entrevistados confirman tres situaciones: descenso de la cantidad de escrituras traslativas de dominio, caída relativa de los precios inmobiliarios y retracción de las obras en construcción, en toda la provincia.

De forma particular, la localidad de Tilcara ha sufrido de manera considerable la falta de movimiento turístico, fruto de la pandemia; que recién para mediados de 2021 retomó las actividades, pero solo con receptivo interno y un flujo cercano al $50 \%$ de lo habitual. Dentro de las posibles medidas, se propone el desarrollo de las cadenas de valor, para así mitigar la dependencia actual con el turismo. Otra posibilidad surge de la propia industria del turismo, con la mejora de la cualificación de la fuerza de trabajo, de cara a la mayor oferta de actividades con nuevos circuitos; hecho que posibilitaría un incremento de la retención del receptivo turístico.

Del mismo modo, se hace necesario, y urgente, un plan de mitigación integral del riesgo, así como la realización de un reordenamiento territorial con sus respectivos códigos de planeamiento urbano para toda la Quebrada; a cargo de una autoridad de control competente y con la participación de la ciudadanía local en la toma de decisión. Sin esto, será muy difícil equilibrar las condiciones fragmentarias del hábitat social existente. Los procesos recientes de gentrificación pueden contrarrestarse con dichas políticas públicas, pero también con recursos financieros; que los municipios no pueden afrontar y que la situación fiscal de la provincia tampoco. No hay que olvidar el acceso a la tierra, cualquier iniciativa de mejoramiento habitacional debe incluir la regularización dominial, el emplazamiento en áreas sin riesgo socioambiental y con servicios básicos, además del crédito hipotecario. Esto último, con el propósito de compensar la demanda de tierra por parte de los actores privados orientados al turismo, seguramente la principal causa de la creciente valorización inmueble sobre la región estudiada.

\section{Referencias}

Benedetti, A. (2010). Quebrada de Humahuaca: ¿hoya, unidad fisiográfica, región geográfica, ambiente o lugar? Estudio bibliográfico sobre la toponimia y el pensamiento geográfico regional argentino (siglos XIX y XX). Revista Registros, 7(7), 111-138. https:// revistasfaud.mdp.edu.ar/registros/article/view/154

Braticevic, S. I. (2018). Valorización inmobiliaria reciente en la Quebrada de Humahuaca. El caso de la localidad de Tilcara, Provincia de Jujuy, Argentina. Economía Sociedad Y Territorio, 56, 291317. https://doi.org/10.22136/est01133 
Costantino, A. (2016). El capital extranjero y el acaparamiento de tierras: conflictos sociales y acumulación por desposesión en Argentina. Revista de Estudios Sociales, 55, 137-149. http://dx.doi. org/10.7440/res55.2016.09

De Toro P., Nocca F., \& Buglione F. (2021). Real Estate Market Responses to the COVID-19 Crisis: Which Prospects for the Metropolitan Area of Naples (Italy)? Urban Science, 5(1), 23. https://doi. org/10.3390/urbansci5010023

Diario El Tribuno de Jujuy. (2004-2018). Relevamiento histórico precios de la tierra en la Quebrada de Humahuaca. Biblioteca del Instituto Interdisciplinario. UBA.

Dirección Provincial de Boletín Oficial e Imprenta del Estado. (2021). Boletín Oficial $N^{\circ}$ 66. Gobierno de la Provincia de Jujuy. http://boletinoficial.jujuy.gob.ar/?p=215358

Dirección Provincial de Estadística y Censos. (2021). Proyecciones y estimaciones. Gobierno de la Provincia de Jujuy. http://dipec.jujuy.gob.ar/ poblacion/proyecciones-y-estimaciones/\#280-281proyecciones-poblacion

FXTOP. (s/f). Cálculo de la inflación y de la evolución de los precios entre dos fechas. http://fxtop.com/es/ calculadora-de-inflacion.php

Gascón, J. \& Cañada, E. (Eds.). (2016). Turismo residencial y gentrificación rural. http://www. pasosonline.org/Publicados/pasosoedita/PSEdita_16 Definitivo_e-book.pdf

Haesbaert, R. (2013). Del mito de la desterritorialización a la multiterritorialidad. Cultura y representaciones sociales, 8(15), 9-42. http://www.scielo.org. $\mathrm{mx} / \mathrm{scielo} . \mathrm{php}$ ? script=sci_arttext\&pid=S2007$81102013000200001 \& \operatorname{lng}=$ es\&tlng=es

Jaramillo, S. (2003). Los fundamentos económicos de la participación en plusvalias [documento inédito]. Lincoln Institute of Land Policy. Universidad de los Andes. https://ordenamientoterritorialcolmayor.files. wordpress.com/2013/02/principios-economicos.pdf

Lorenzen, M.(2021). Rural gentrification, touristification, and displacement: Analysing evidence from Mexico. Journal of Rural Studies, 86, 62-75. https://doi. org/10.1016/j.jrurstud.2021.05.015
Mendoza, F. (2016). La gentrificación en los estudios urbanos: una exploración sobre la producción académica de las ciudades. Cadernos Metrópole, 18(37), 697-719. https://doi.org/10.1590/22369996.2016-3704

Minaglia, N. \& Bages, C. (2020). Mapeo de la Quebrada de Humahuaca. Precios inmobiliarios [mapeo inédito]. Tilcara.

Ministerio de Educación de la Nación. (2021). Mapoteca Educ.ar de la Provincia de Jujuy.: http://mapoteca. educ.ar/.files/index.html.1.12.html

Ministerio del Interior, Obras Públicas y Vivienda de la Nación. (2016). Programa Integral de Hábitat. Lineamientos para la Localidad de Tilcara.

Municipalidad de Tilcara. (2018). Datos de actividades económicas del Municipio de Tilcara [informe no publicado]. Jefatura de Gabinete.

Navegación Aérea Argentina. (2018). Informe Mensual Diciembre. Departamento de Estadística. Empresa Argentina de Navegación Aérea (EANA). Ministerio de Transporte. https://www.eana.com.ar/sites/default/ files/2019-01/Informe\%20Mensual\%20201812_1. pdf

Ochoa, P. (2017). Arquitectura para la materialización del poder. Aportes a partir del estudio de nuevos sitios detectados en la Quebrada de Sixilera (Quebrada de Humahuaca, Argentina). Mundo de Antes, 11, 171-194. http://mundodeantes.org.ar/aheadofprint/04-Ochoa.pdf

Ortiz Flores, E. (2012). Producción Social de la Vivienda y el Hábitat. Bases Conceptuales y Correlación con los Procesos Habitacionales. https://hic-al. org/2018/12/28/produccion-social-de-la-vivienda-yel-habitat-bases-conceptuales-y-correlacion-con-losprocesos-habitacionales/

Parias Durán, A. (2010). Reseña de "Hacia una teoría de la renta del suelo urbano" de Samuel Jaramillo González. Territorios, 22,151-161. https://www. redalyc.org/articulo.oa? $\mathrm{id}=35714236008$

Potocko, A. (2013). Entre el Estado y la sociedad: procesos de transformación del territorio: El caso del barrio Sumay Pacha en la Quebrada de Humahuaca. Revista Registros, 10, 95-111. https://revistasfaud. mdp.edu.ar/registros/article/view/73 
Tommei, C. (2010). Transformaciones del hábitat. Purmamarca después de la apertura del Paso de Jama y de la declaratoria Unesco. Borradores IAA, 1, 2-17. http://www.iaa.fadu.uba.ar/publicaciones/ borradores/Borrador_IAA_01.pdf

Tommei, C. \& Benedetti, A. (2014). De ciudad-huerta a pueblo boutique: Turismo y transformaciones materiales en Purmamarca. Revista de geografía Norte Grande, 58, 161-177. https://dx.doi.org/10.4067/ S0718-34022014000200010

Vecslir, L. \& Tommei, C. (2013). Hacia un proyecto territorial para un paisaje cultural. La Quebrada de Humahuaca, Jujuy, Argentina. Revista Bitácora Urbano Territorial, 22(1), 61-74. https://dialnet. unirioja.es/servlet/articulo? codigo $=5001850$ 